\title{
The Effects of Polydeoxyribonucleotide on the Survival of Random Pattern Skin Flaps in Rats
}

\author{
Kun Il Chung, Han Koo Kim, Woo Seob Kim, Tae Hui Bae \\ Department of Plastic and Reconstructive Surgery, Chung-Ang University Hospital, Chung-Ang University College of Medicine, Seoul, Korea
}

Background Partial or complete necrosis of a skin flap is a common problem. Polydeoxyribonucleotide (PDRN) can be extracted from trout sperm and used as a tissue repair agent. The aim of this study was to investigate whether PDRN could improve the survival of random pattern skin flaps in rats.

Methods Twenty-two male Sprague-Dawley rats were randomly divided into two groups: the PDRN treatment group $(n=11)$ and the control group $(n=11)$. Caudally pedicled random pattern skin flaps were elevated on their dorsal skin and resutured. The treatment group received daily intraperitoneal administration of PDRN ( $8 \mathrm{mg} / \mathrm{kg} / \mathrm{day})$, and the control group received fluid vehicle $(\mathrm{NaCl} 0.9 \%, 8 \mathrm{mg} / \mathrm{kg} /$ day $)$ from day 0 to day 6 . On day 7 , the flap survival was evaluated and the harvested tissue surrounding the demarcation line of the necrotic area was stained with $\mathrm{H \& E}$, anti-rat vascular endothelial cell growth factor (VEGF) antibody, and PECAM-1/CD31 antibody.

Results The average necrotic area of the flap in the PDRN group was significantly smaller when compared with that of the control group. Histologic and immunohistochemical evaluation showed that granulation thickness score and VEGF-positive staining cells were marked higher in the PDRN group than in the control group. PECAM-1/CD31-positive microvascular densities were significantly higher in the PDRN group when compared with the control group. Conclusions This study confirms that PDRN improves the survival of random pattern skin flaps in rats. These results may represent a new therapeutic approach to enhancing flap viability and achieving faster wound repair.

Keywords Polydeoxyribonucleotides / Surgical flaps / Angiogenesis modulating agents / Vascular endothelial growth factors / Antigens, CD31

Received: 21 Jan 2013 • Revised: 25 Feb 2013 • Accepted: 18 Mar 2013

pISSN: 2234-6163 • elSSN: 2234-6171 • http://dx.doi.org/10.5999/aps.2013.40.3.181 • Arch Plast Surg 2013;40:181-186
Correspondence: Han Koo Kim Department of Plastic and Reconstructive Surgery, Chung-Ang University Hospital, Chung-Ang University College of Medicine, 102 Heukseok-ro, Dongjak-gu, Seoul 156-755, Korea

Tel: +82-2-6299-1615

Fax: +82-2-825-9880

E-mail: hkkiim@cau.ac.kr
No potential conflict of interest relevant to this article was reported.

\section{INTRODUCTION}

Local skin flap procedures are often used in plastic and reconstructive surgery to repair tissue defects. Among local skin flap procedures, random pattern skin flaps are a reliable and convenient procedure. However, after random pattern skin flap surgery, partial or complete distal flap necrosis is a common problem. Many trials have investigated ways to reduce distal flap necrosis. The delayed procedure can be very useful, but requires additional surgical interventions, takes a great deal of time, and can also be invasive. Previous research has shown that systemic and/or local drug agents can help overcome flap loss

Copyright $(\odot 2013$ The Korean Society of Plastic and Reconstructive Surgeons

This is an Open Access article distributed under the terms of the Creative Commons Attribution Non-Commercial License (http://creativecommons.org/

licenses/by-nc/3.0/) which permits unrestricted non-commercial use, distribution, and reproduction in any medium, provided the original work is properly cited.

www.e-aps.org 
by inducing angiogenesis $[1,2]$. To increase neovascularization, various angiogenic growth factors such as vascular endothelial cell growth factor (VEGF), transforming growth factor (TGF), fibroblast growth factor, and platelet-derived growth factor are all important [3-6].

Polydeoxyribonucleotide (PDRN) from human placenta has been characterized and quantitated, and it was found to act in wound healing by stimulating the tissue repair process [7]. PDRN extracted from trout sperm was recently found to be a tissue repair agent like the PDRN from human placenta. The drug agent can be obtained through a high temperature extraction process and contains over $95 \%$ pure active principle without additional pharmacologically active proteins and peptides (Registration Dossier, Italian Ministry of Health) [8]. This compound holds deoxyribonucleotide polymers with chain lengths ranging from 50 to 2,000 base pairs and represents the source of purine and pyrimidine deoxynucleosides/deoxyribonucleotides and bases [9].

PDRN activates the $A_{2 \mathrm{~A}}$ receptor subtype of adenosine receptors and then stimulates VEGF release as well as fibroblast maturation in skin wounds [9]. In prior studies, stimulation of the adenosine $A_{2 A}$ receptor was found to lead to an increase in VEGF products, fibroblast differentiation and maturation, and the acceleration of granulation tissue formation rates and the wound repair process $[10,11]$.

The aim of this study was to investigate whether PDRN could improve the survival of random pattern skin flaps in rats.

\section{METHODS}

\section{Animal models}

The experimental protocol, including the use of animals in the research, was approved by the Institutional Animal Care and Use Committee, Chung-Ang University, Korea.

Twenty-two male Sprague-Dawley rats aged 7 weeks and weighting 250 to $300 \mathrm{~g}$ were randomly divided into two groups: the PDRN treatment group $(\mathrm{n}=11)$ and the control group $(\mathrm{n}=$ 11). All of the animals were provided with standard laboratory food and water ad libitum.

\section{Random pattern skin flaps and PDRN procedure}

The surgical procedure was performed under general anesthesia initiated by intramuscular injection of $50 \mathrm{mg} / \mathrm{kg}$ of tiletamine/ zolazepam (Zoletil 50, Virbac S.A, Carros, France) and $5 \mathrm{mg} /$ $\mathrm{kg}$ of xylazine hydrochloride (Rompun, Bayer Korea Inc., Seoul, Korea). Under aseptic conditions, the rats were shaved with an electric shaver, and caudally pedicled McFarlane-type [12] 3 $\mathrm{cm} \times 9 \mathrm{~cm}$ random pattern skin flap was made on the dorsal skin of each one. The flap was elevated in a plane deep to the panniculus carnosus. After controlling any bleeding, the flap wound edges were closed using 4-0 black silk.

Following the surgical procedure, the rats in the treatment group received daily intraperitoneal administration of PDRN (Placentex Integro, Mastelli Srl, Sanremo, Italy) at a dosage of 8 $\mathrm{mg} / \mathrm{kg} /$ day (day 0 to 6 ). The control groups received intraperitoneal injections of the fluid vehicle $(\mathrm{NaCl} 0.9 \%)$ at the same volume and time as the treatment group. The appropriate dose of PDRN was chosen according to previous investigations reporting that the $8 \mathrm{mg} / \mathrm{kg} /$ day dose was the most effective dose for improving wound healing in genetically diabetic mice and for improving blood flow in an experimental model of peripheral artery occlusive disease $[9,13]$.

\section{Flap survival measurement}

Flap survival was evaluated on the seventh postoperative day. In both groups, relatively definite demarcated lines of distal necrosis were seen. The necrotic area was dark, hard, and did not bleed when cut with a scalpel. Under general anesthesia as described above, the necrotic flap area was assessed with digital photos (single-lens reflex camera with $60 \mathrm{~mm}$ macro lens, EOS 350D, Canon). Using ImageJ software (National Institutes of Health image), the necrotic area was compared to the total flap area, and was calculated as a percentage.

\section{Histologic examination}

On the seventh postoperative day, all of the rats were sacrificed. The $1 \mathrm{~cm} \times 1 \mathrm{~cm}$ full-thickness tissue surrounding the demarcation line of the necrotic area was harvested, including samples from both the necrotic and the survival area. All of the tissue specimens were fixed in $10 \%$ neutral-buffered formalin for at least 24 hours at room temperature, embedded in paraffin, and sectioned in $4 \mu \mathrm{m}$ slices perpendicular to the anterior-posterior axis. Each section was stained with hematoxylin and eosin (H\&E) according to the standard protocol. The slide sections were evaluated by two pathologists blinded to the treatment, under a microscope at $100 \times$ and $200 \times$ magnification. The histologic score of the granulation tissue thickness was assigned using our own scoring system (score $1,<10 \mu \mathrm{m} ; 2,10-30 \mu \mathrm{m} ; 3$, 30-50 $\mu \mathrm{m} ; 4,>50 \mu \mathrm{m}, 100 \times$ magnification).

\section{Immunohistochemistry}

Paraffin-embedded and $4 \mu \mathrm{m}$ sectioned tissue samples were immunostained with primary antibody against rat VEGF (1:100 dilution, 1 hour at room temperature, Santa Cruz Biotechnology, Santa Cruz, CA, USA) and platelet cell adhesion molecule-1 (PECAM-1)/CD31 (1:250 dilution, 1 hour at room 
temperature, Santa Cruz Biotechnology). Secondary antibody was provided by the UltraVision LP Detection System (35 minutes at room temperature, Thermo Scientific, Pittsburgh, MA, USA). The 3-amino-9-ethyl carbazole substrate system (Spring Bioscience, Lab Vision, Fremont, CA, USA) was used for color development. Lastly, the sections were counterstained with Mayer's hematoxylin and mounted.

The number of VEGF-positive cells was quantified in at least 5 fields per specimen $(\times 400)$. The PECAM-1/CD31-positive microvascular density was also estimated by counting in at least 5 fields per specimen $(\times 400)$. The two pathologists were blinded to the specimen identity.

\section{Statistical analysis}

The results are expressed as mean \pm standard deviation. Statistical analyses were performed using statistical software (SPSS for ver. 16.0, SPSS Inc., Chicago, IL, USA). A P-value $<0.05$ was considered statistically significant. The degree of necrotic change, as well as histologic and immunohistochemistry results were compared using the Mann-Whitney test.

\section{Table 1. Flap necrosis in the treatment and control groups}

\begin{tabular}{|lcc|}
\hline Animal number & $\begin{array}{c}\text { PDRN treatment } \\
\text { group (\%) }\end{array}$ & $\begin{array}{c}\text { Control } \\
\text { group (\%) }\end{array}$ \\
\hline 1 & 20.71 & 26.15 \\
2 & 26.62 & 26.12 \\
3 & 15.12 & 39.86 \\
4 & 33.39 & 38.00 \\
5 & 17.14 & 27.24 \\
6 & 27.98 & 34.87 \\
7 & 18.28 & 42.80 \\
8 & 18.21 & 28.69 \\
9 & 21.18 & 36.79 \\
10 & 20.82 & 33.71 \\
11 & 10.80 & 43.44 \\
Mean \pm SD & $20.93 \pm 6.35$ & $34.33 \pm 6.50$ \\
\hline PDRN, polydeoxyribonucleotide; SD, standard deviation. \\
\hline
\end{tabular}

\section{RESULTS}

\section{PDRN increased the survival of random pattern skin flaps}

The average necrotic area of the flap in the PDRN group was significantly smaller when compared with that of the control group (PDRN treatment, $20.93 \% \pm 6.35 \%$; control, $34.33 \% \pm 6.50 \%$; $\mathrm{P}=0.001)$ (Table 1, Fig. 1).

\section{PDRN increased granulation tissue formation, VEGF expression, and neovascularization}

On histologic evaluation, the granulation tissue thickness score was significantly higher in the PDRN group, as compared with the control group (PDRN treatment, 3.27 \pm 0.64 ; control, 1.72 $\pm 0.78 ; \mathrm{P}=0.001$ ) (Fig. 2). Immunohistochemistry evaluation showed more VEGF-positive staining cells in the PDRN group than in the control group (PDRN treatment, $120.64 \pm 20.38$ /field; control, $87.09 \pm 13.51 /$ field; $\mathrm{P}=0.001$ ) (Fig. 3). The PECAM-1/CD31-positive microvascular densities were significantly higher in the PDRN group when compared with the control group (PDRN treatment, 30.36 \pm 9.34 /field; control, $18.45 \pm 5.89 /$ field; $\mathrm{P}=0.005$ ) (Fig. 4).

\section{DISCUSSION}

Flap reconstruction procedures are frequently performed in plastic and reconstructive surgery. Although there are various types of procedures to cover a defect such as free flaps and perforator flaps, random pattern skin flaps have been used for a long time, and are easy to handle and reliable. However, their main drawback is in the unpredictable occurrence of necrosis of the distal portion and distal flap. If distal flap necrosis occurs, additional procedures and unavoidable long healing times are required. Much research about the survival and wound healing of random pattern skin flaps have been studied in many diverse

\section{Fig. 1. Postoperative photographs of random pattern skin flaps}

Photographs of random pattern skin flaps in the polydeoxyribonucleotide (PDRN) treatment group $(A, B, C)$ and control group $(D, E, F)$ on the seventh postoperative day. The necrotic tissue areas were significantly deemphasized in the treatment group, compared with the control group.
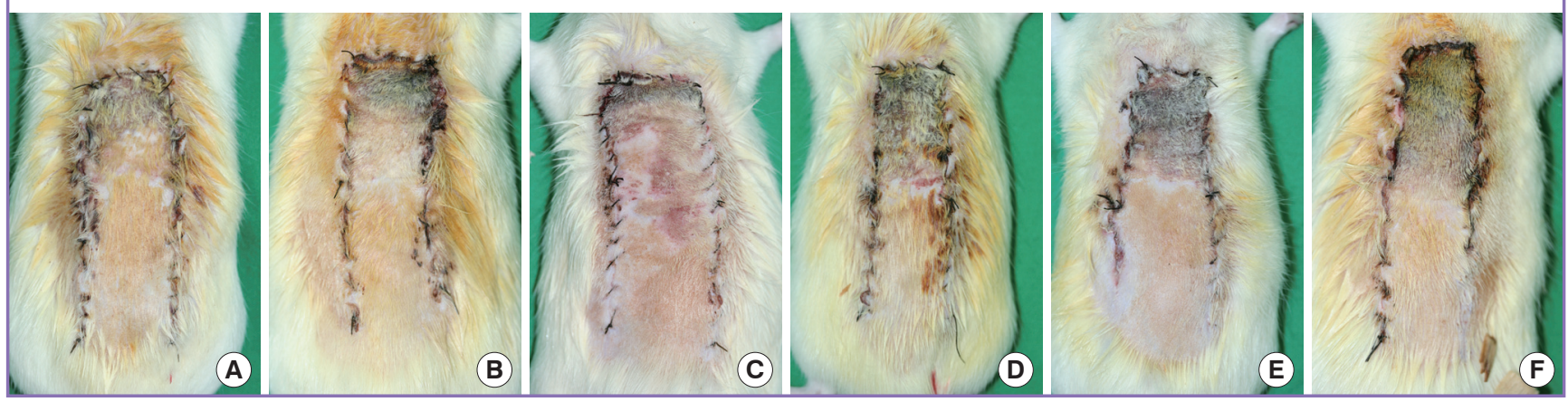


\section{Fig. 2. Histologic evaluation about granulation tissue thickness}

Histologic findings $(H \& E, \times 200)$ in the PDRN treatment group $(A)$ and the control group $(B)$ on the seventh postoperative day. The black arrows indicate granulation tissue (violet color) in (A), but there is no definite granulation tissue visible in (B). (C) Histologic scores of granulation tissue thickness. PDRN, polydeoxyribonucleotide. ${ }^{\text {al }} \mathrm{P}=0.001$ vs. control.
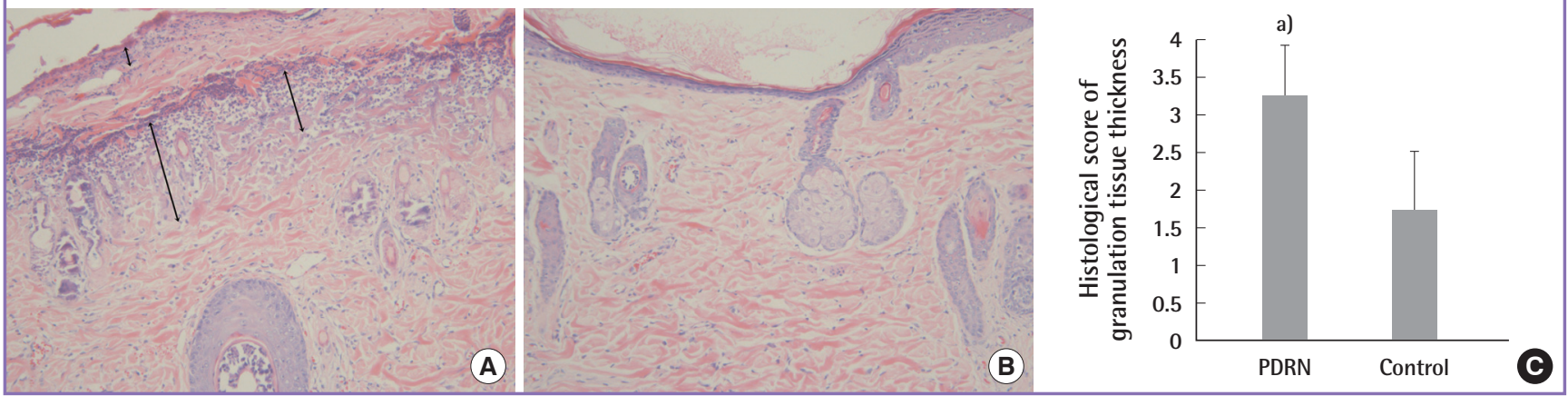

\section{Fig. 3. Immunohistochemistry evaluation by immune-staining against VEGF}

Immunohistochemical staining of Ab-VEGF $(\times 400)$ showed more VEGF-positive cells (brown) in the PDRN treatment group (A) than in the control group (B). (C) The VEGF-positive cell count was estimated. VEGF, vascular endothelial cell growth factor; PDRN, polydeoxyribonucleotide. ${ }^{\text {a) } P=0.001}$ vs. control.
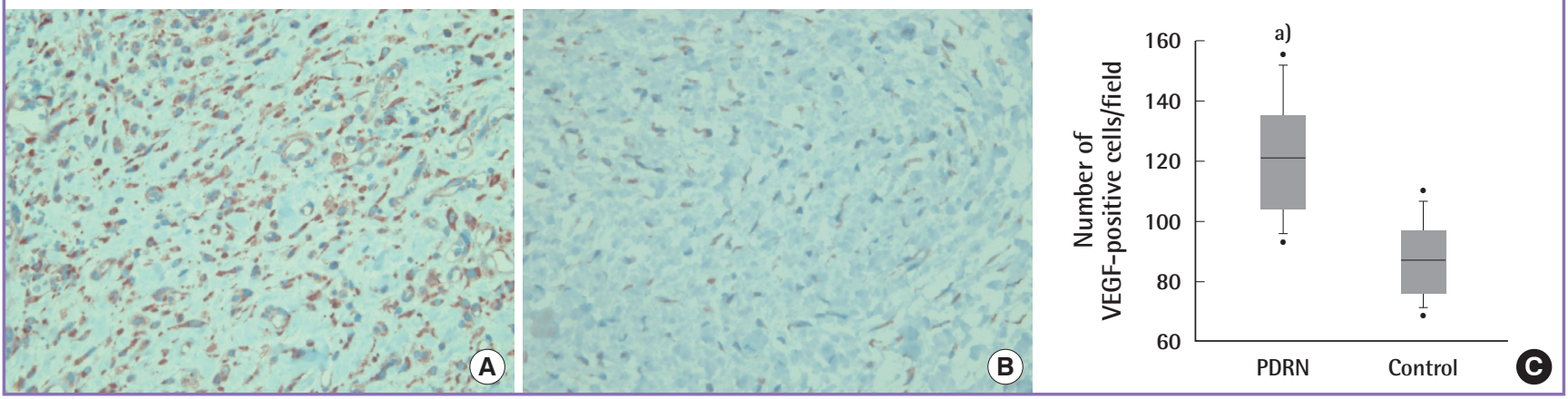

Fig. 4. Immunohistochemistry evaluation by immune-staining against PECAM-1/CD31

Immune-staining against PECAM-1/CD31 ( $\times 400)$ showed significantly more PECAM-1 positive microvessels (circular red-brown) in the PDRN treatment group (A) than in the control group (B). (C) The estimated microvascular density. PECAM-1, platelet cell adhesion molecule-1; PDRN, polydeoxyribonucleotide. ${ }^{\text {al }} \mathrm{P}=0.005$ vs. control.
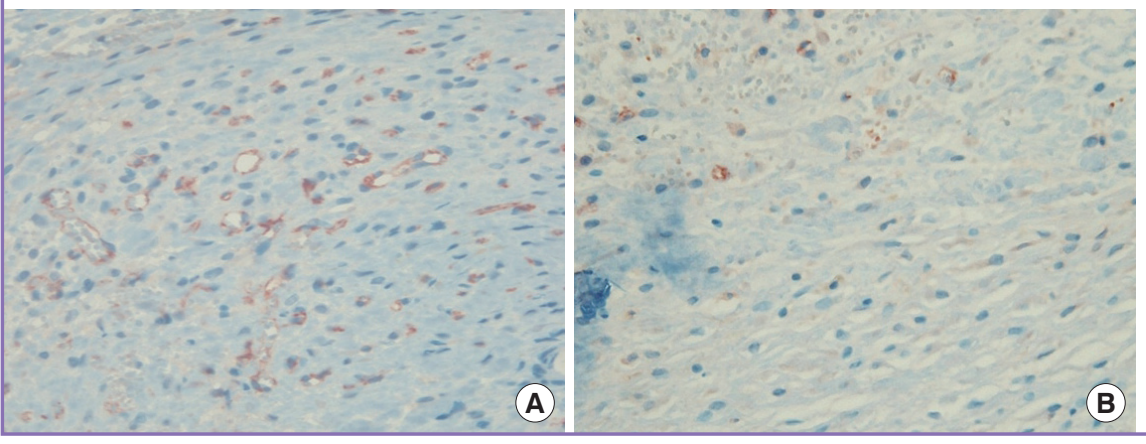

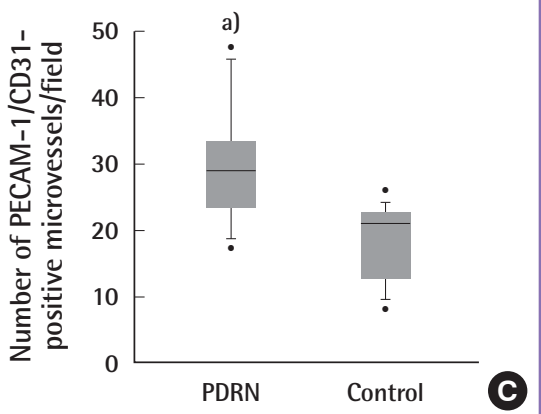

skin flap necrosis $[10,14]$.

Various studies have demonstrated the effects of nucleotides and nucleosides on wound healing. Nucleotides and nucleosides act in different ways. They stimulate nucleic acid synthesis through the salvage pathway and bind to purinergic receptors. Purinergic receptors are divided into two subclasses, P1 and P2, which respond to nucleosides and nucleotides, respectively. P1 
are subdivided in $\mathrm{A} 1, \mathrm{~A} 2 \mathrm{~A} / 2 \mathrm{~B}$, and $\mathrm{A} 3$ subtypes, while $\mathrm{P} 2$ receptors include a number of subtypes designated as P2X,Y,U,Z [15]. Among the purinergic receptors, PDRN acts on adenosine $\mathrm{A} 2 \mathrm{~A}$ receptors (a $\mathrm{P} 1$ subclass). Activation of the adenosine A2A receptors stimulates endothelial cell proliferation, migration, and secretion of VEGF, and reduces inflammation. It also acts as a stimulant on cell lines such as osteoblasts, fibroblasts, pre-adipocytes, and collagen $[10,11,16,17]$. The administration of PDRN improves granulation tissue proliferation, which can be reversed by administering 3,7-dimethyl-1-propargylxanthine (DMPX, a selective A2A receptor antagonist). Stimulation of the A2A receptor induces activation of a $\mathrm{G}$ protein leading to cyclic AMP (cAMP) signaling, activation of protein kinase A, and cell proliferation [16]. In previous studies, PDRN was used as an angiogenesis stimulator and wound healing agent in diabetic mice [9]; in cases of thermal injury [18], it has been shown to improve blood flow in peripheral artery occlusive disease in rats [13], enhances the growth rate of human fibroblasts and osteoblasts in in vitro models [19], and restores blood flow in ischemic skin flaps [20]. In addition, PDRN has been shown to stimulate corneal epithelium regeneration after photorefractive keratectomy and myopic stigmatic defects [21] and accelerates the wound healing of graft donor sites $[22,23]$. These led us to hypothesize that PDRN could have beneficial results in a rat model of random pattern skin flaps.

In our study, PDRN successfully improved flap survival. On the seventh postoperative day, we found that the areas of necrotic tissue of mice in the PDRN group were significantly smaller than in the control group. The effects of PDRN correlated well with the histologic and immunohistochemistry findings of increasing granulation tissue proliferation, VEGF expression, and neovascularization. We calculated the granulation tissue thickness using our scoring system with the following parameters (score $1,<10 \mu \mathrm{m} ; 2,10-30 \mu \mathrm{m} ; 3,30-50 \mu \mathrm{m} ; 4$; > $50 \mu \mathrm{m} ; 100 \times$ magnification). The high score indicated that PDRN quantitatively and qualitatively improved wound healing. The marked effects of PDRN on angiogenesis were further demonstrated through expression of an anti-VEGF antibody, PECAM-1/CD31. There results show that PDRN induces angiogenesis and increases flap survival in rats.

In recent studies, PDRN has not shown any toxicity in primary cultures of rat macrophages, nor has it shown any antigenic properties. The administration of PDRN has not caused death, nor had any toxic effects on the liver, lungs, brain, skeletal muscle, or heart in rats and mice $[9,13]$. Induced angiogenesis was not observed in the aforementioned organs [24]. PDRN is now approved in Italy for both parenteral and topical use (Registration Dossier, Ministry of Health) [13]. This suggests that PDRN may be a safe agent to use in humans and can be expected to be a valuable agent in flap surgery and various wound healing processes requiring angiogenesis. However, further in vivo and in vitro studies on its side effects are necessary for long laboratory periods.

This study confirms the positive effects of PDRN on the survival of random pattern skin flaps in rats. The underlying mechanism is likely to be related to the activation of the PDRNadenosine $\mathrm{A}_{2 \mathrm{~A}}$ receptor-VEGF pathway. These results may represent a new therapeutic approach to enhancing flap viability and achieving faster wound repair. Further in vivo studies are needed to fully understand the benefits and limits of PDRN and wound healing.

\section{REFERENCES}

1. Folkman J, Shing Y. Angiogenesis. J Biol Chem 1992;267: 10931-4.

2. Akhavani MA, Sivakumar B, Paleolog EM, et al. Angiogenesis and plastic surgery. J Plast Reconstr Aesthet Surg 2008; 61:1425-37.

3. Padubidri A, Browne E Jr. Effect of vascular endothelial growth factor (VEGF) on survival of random extension of axial pattern skin flaps in the rat. Ann Plast Surg 1996;37: 604-11.

4. Kryger Z, Zhang F, Dogan T, et al. The effects of VEGF on survival of a random flap in the rat: examination of various routes of administration. Br J Plast Surg 2000;53:234-9.

5. Pierce GF, Tarpley JE, Yanagihara D, et al. Platelet-derived growth factor (BB homodimer), transforming growth factor-beta 1 , and basic fibroblast growth factor in dermal wound healing. Neovessel and matrix formation and cessation of repair. Am J Pathol 1992;140:1375-88.

6. Shukla A, Dubey MP, Srivastava R, et al. Differential expression of proteins during healing of cutaneous wounds in experimental normal and chronic models. Biochem Biophys Res Commun 1998;244:434-9.

7. Tonello G, Daglio M, Zaccarelli N, et al. Characterization and quantitation of the active polynucleotide fraction (PDRN) from human placenta, a tissue repair stimulating agent. J Pharm Biomed Anal 1996;14:1555-60.

8. Bianchini P, Tellini N, Morani AM, et al. Pharmacological data on polydeoxyribonucleotide of human placenta. Int J Tissue React 1981;3:151-4.

9. Galeano M, Bitto A, Altavilla D, et al. Polydeoxyribonucleotide stimulates angiogenesis and wound healing in the genetically diabetic mouse. Wound Repair Regen 2008;16: 208-17. 
10. Montesinos MC, Desai A, Chen JF, et al. Adenosine promotes wound healing and mediates angiogenesis in response to tissue injury via occupancy of $\mathrm{A}(2 \mathrm{~A})$ receptors. Am J Pathol 2002;160:2009-18.

11. Montesinos MC, Gadangi P, Longaker M, et al. Wound healing is accelerated by agonists of adenosine A2 (G alpha s-linked) receptors. J Exp Med 1997; 186:1615-20.

12. McFarlane RM, Deyoung G, Henry RA. The Design of a Pedicle Flap in the Rat to Study Necrosis and Its Prevention. Plast Reconstr Surg 1965;35:177-82.

13. Bitto A, Polito F, Altavilla D, et al. Polydeoxyribonucleotide (PDRN) restores blood flow in an experimental model of peripheral artery occlusive disease. J Vasc Surg 2008;48: 1292-300.

14. Gurunluoglu R, Meirer R, Shafighi M, et al. Gene therapy with adenovirus-mediated VEGF enhances skin flap prefabrication. Microsurgery 2005;25:433-41.

15. Thellung S, Florio T, Maragliano A, et al. Polydeoxyribonucleotides enhance the proliferation of human skin fibroblasts: involvement of A2 purinergic receptor subtypes. Life Sci 1999;64:1661-74.

16. Altavilla D, Squadrito F, Polito F, et al. Activation of adenosine $\mathrm{A} 2 \mathrm{~A}$ receptors restores the altered cell-cycle machinery during impaired wound healing in genetically diabetic mice. Surgery 2011;149:253-61.

17. Guizzardi S, Galli C, Govoni P, et al. Polydeoxyribonucleotide (PDRN) promotes human osteoblast proliferation: a new proposal for bone tissue repair. Life Sci 2003;73:1973-
83.

18. Bitto A, Galeano M, Squadrito F, et al. Polydeoxyribonucleotide improves angiogenesis and wound healing in experimental thermal injury. Crit Care Med 2008;36:1594-602.

19. Sini P, Denti A, Cattarini G, et al. Effect of polydeoxyribonucleotides on human fibroblasts in primary culture. Cell Biochem Funct 1999;17:107-14.

20. Polito F, Bitto A, Galeano M, et al. Polydeoxyribonucleotide restores blood flow in an experimental model of ischemic skin flaps. J Vasc Surg 2012;55:479-88.

21. Lazzarotto M, Tomasello EM, Caporossi A. Clinical evaluation of corneal epithelialization after photorefractive keratectomy in patients treated with polydeoxyribonucleotide (PDRN) eye drops: a randomized, double-blind, placebocontrolled trial. Eur J Ophthalmol 2004;14:284-9.

22. Rubegni P, De Aloe G, Mazzatenta C, et al. Clinical evaluation of the trophic effect of polydeoxyribonucleotide (PDRN) in patients undergoing skin explants. A Pilot Study. Curr Med Res Opin 2001; 17:128-31.

23. De Aloe G, Rubegni P, Biagioli M, et al. Skin graft donor site and use of polydeoxyribonucleotide as a treatment for skin regeneration: a randomized, controlled, double-blind, clinical trial. Wounds 2004;16:258-63.

24. Altavilla D, Bitto A, Polito F, et al. Polydeoxyribonucleotide (PDRN): a safe approach to induce therapeutic angiogenesis in peripheral artery occlusive disease and in diabetic foot ulcers. Cardiovasc Hematol Agents Med Chem 2009; 7:31321. 